the liver, which was accompanied by lethargy, weakness, and hypotonia. One of these patients died, but the others responded to a high protein, high carbohydrate, and low fat diet. Transient diarrhoea and vomiting were common but usually settled by three months. Persistent diarrhoea occurred in only four of the patients.

Weismann ${ }^{8}$ has reported his experience with 123 patients undergoing jejuno-ileal bypass. This operation was supplemented in 80 cases by a panniculectomy, in which the abdominal apron of superficial fat was excised (a procedure which has been nicknamed "apronectomy"). Two patients died from pulmonary embolism and one patient died six months after surgery with advanced necrosis of the liver. Two patients required reversal of the operation, one because of severe persistent vomiting and malnutrition and the other because of the development of severe ulcerative colitis. A dramatic loss of weight in this series was maintained in patients followed up over two to three years. Careful postoperative metabolic studies showed depression of the serum potassium until diarrhoea came under control. The serum cholesterol was reduced and remained low. The Schilling test gave results well below normal and the glucose tolerance curve was flattened for up to two years or more postoperatively. This last appears to be a satisfactory laboratory assessment of the adequacy of the bypass procedure. Liver biopsy studies carried out in 88 patients at the time of operation showed mild to severe fatty infiltration. Forty patients had subsequent biopsies performed at intervals of 10 days to three years after surgery. The general pattern was of continued fatty infiltration between 6 and 12 months after operation and then a decrease in the subsequent 12 months. No progressive cirrhotic changes were observed. The patients adapted well to the malabsorption state and in the long term only vitamin $\mathrm{B}_{1_{2}}$ must be given indefinitely.

Baber and his colleagues ${ }^{9}$ in their series of 90 patients undergoing bypass had only two deaths, both from liver failure, but two more patients had to have the bypass taken down for progressive liver disease. Their serial biopsy studies also suggest continued progression in the fatty infiltration of the liver for the first year after operation and then improvement.

Schwartz and his colleagues ${ }^{10}$ note that these fairly severe operations can be performed on grossly obese and often poorrisk patients with a reasonably low morbidity and mortality. In their series of 94 cases there was only one death from a perforation of an acute stress ulcer of the colon. As might be expected in this type of patient, wound infection and pulmonary emboli are often reported, and, interestingly enough, stress ulceration of the stomach occurs from time to time. Payne and his colleagues, ${ }^{11}$ with the most extensive experience of this type of surgery, now amounting to 165 bypass operations spread over 16 years, report a $6^{\circ}{ }_{0}$ mortality, a risk which is becoming even lower in recent years. Corso and Joseph ${ }^{12}$ have had no deaths in their 34 operations performed since 1970.

The mortality and morbidity of this operation must be pitted against the poor long-term prognosis of the massively obese patient who fails to respond to the most stringent medical treatment. Though the late results of the operation have still not been fully assessed, particularly the risk of eventual nutritional deficiencies and the development of hepatic cirrhosis, the procedure appears to have a good record for rehabilitation of these unfortunate people back to a useful active life. \footnotetext{
${ }^{1}$ Payne, J. H., DeWind, L. T., and Commons, R. R., American fournal of
Surgery, 1963, 106, 273.
}

2 Payne, J. H., and DeWind, L. T., American fournal of Surgery, 1969, 118, 14

${ }^{3}$ Schwartz, H., and Jensen, H. E., Acta Chirurgica Scandinavica, 1973, 139, 551.

${ }^{4}$ Hallberg, D., and Backman, L., Acta Chirurgica Scandinavica, 1973, 139, 557.

${ }^{5}$ Scott, H. W., et al., Annals of Surgery, 1973, 177, 723.

6 Baddeley, R. M., British Fournal of Surgery, 1973, 60, 903.

'Baddeley, R. M., Proceedings of the Royal Society' of Medicine, 1973, 66, 1098.

8 Weismann, R. E., American fournal of Surgery, 1973, 125, 437.

${ }^{9}$ Baber, J. C., Hayden, W. F., and Thompson, B. W., American fournal of

Surgery, 1973, 126, 769.
10 Schwartz, M. Z., Varco, R. L., and Buchwald, H., fournal of Surgical Research, 1973, 14, 147.

11 Payne, J. H., et al., Archives of Surgery, 1973, 106, 432.

12 Corso, P. J., and Joseph, W. L., Surgery, Gynecology and Obstetrics, $1974,138,1$.

\section{Conversations on the Social Services}

Some obvious unease about the working of the social services Act was evident at last year's Annual Representative Meeting and clearly reflected widespread concern among doctors. Later in the year a survey by the G.M.S. Committee confirmed that most local medical committees thought that social workers were less co-operative and that their standards of training had fallen since the introduction of the Seebohm proposals, particularly in services for the mentally ill and handicapped. Regional committees for hospital medical services reported that social-work standards had fallen in hospitals; and indeed the new, generic social workers seemed to many doctors to give medicine a low priority.

The Seebohm removal of the social services from medical control caused a massive administrative upheaval against a background of impending large-scale alterations in the Health Service itself. A year after the shout of anger at Folkestone it might reasonably be asked whether things are still as bad, and if so why-a change of attitudes, poor communications, or shortage of people and money. To try and answer some of these questions we start this week a short series of "Medical Practice" articles reporting conversations with various individuals-general practitioners, consultants, and social workers. The first article, giving the views of two rural general practitioners, on their relationships with the social services, appears at p. 595.

\section{Attractions at Hull}

In comparison with ten years ago doctors looking for postgraduate teaching sessions have an enormous range to choose from. While it may be simpler for them to confine themselves to occasional lunchtime and evening sessions close to home, there is a lot to be said in favour of getting away for a few days. Talking shop with colleagues from other parts of the country makes a stimulating change from the round of familiar faces at local meetings. This is especially true when an attractive programme is offered, as it is at the B.M.A. Scientific Meeting at Hull next month.

Full details of the sessions are given in the Supplement at p. 107. The main topics are medical intervention-questioning whether treatment is always justifiable; the management of pain; communications in medicine; cancer; and doctors and machines. As usual at these meetings a programme of social and cultural events has been arranged for non-medical members of doctors' families. Application for registration should be sent as soon as possible. 